\title{
Equations for predicting tree height, total volume, and product recovery for black spruce (Picea mariana) plantations in northeastern Quebec
}

\author{
by Chuangmin Liu ${ }^{1}$ and S.Y. Zhang ${ }^{2}$
}

\begin{abstract}
Several regression models with different independent variables were studied for their ability to predict total tree height, total stem volume, and product recoveries (lumber volume, chip volume, lumber value, and total product value) from a sawing simulator. A sample of 172 trees from black spruce plantations was used to fit model parameters and another independent sample of 139 trees was used for model evaluation. The sample encompassed large variations in tree characteristics and tree product recovery. All the fitted models were suitable for predicting their corresponding response variables. Model validation through actual product recovery data from a real stud mill further indicated that the general tree-level models for the product recovery were able to accurately predict product recovery, especially from small- and mediumsized trees, using measured tree characteristics. These models provide a valuable tool for forest managers in determining appropriate management strategies (e.g., stand volume and optimizing stand value).
\end{abstract}

Key words: black spruce, regression analysis, tree characteristics, product recovery, sawing simulation

\begin{abstract}
RÉSUMÉ
Quelques modèles de régression selon différentes variables indépendantes ont été étudiés pour leur capacité à prédire la hauteur totale de l'arbre, le volume total de la tige et les produits retirés (volume de sciage, volume de copeaux, valeur du sciage et valeur totale des produits) au moyen d'un simulateur de sciage de bois d'œuvre. Un échantillon de 172 tiges d'épinette noire en provenance de plantations a été utilisé pour ajuster les paramètres du modèle et un autre échantillon indépendant de 139 tiges a été utilisé pour l'évaluation du modèle. L'échantillon comprenait une forte variation au niveau des caractéristiques des tiges et des produits tirés de ces tiges. Tous les modèles ajustés étaient utilisables pour prédire leurs variables correspondantes de réponse. La validation du modèle au moyen des données réelles de produits en provenance d'une vraie scierie a indiqué que les modèles généraux au niveau de l'arbre en matière de produits retirés sont en mesure de prédire avec précision la production retirée, particulièrement à partir d'arbres de petite et de moyenne taille, au moyen des caractéristiques mesurées de ces arbres. Ces modèles constituent un outil utile pour les aménagistes forestiers au moment du choix des stratégies adéquates d'aménagement (par ex, volume du peuplement et optimisation de la valeur du peuplement).
\end{abstract}

Mots clés : épinette noire, analyse de régression, caractéristiques des tiges, produits retirés, simulation de sciage

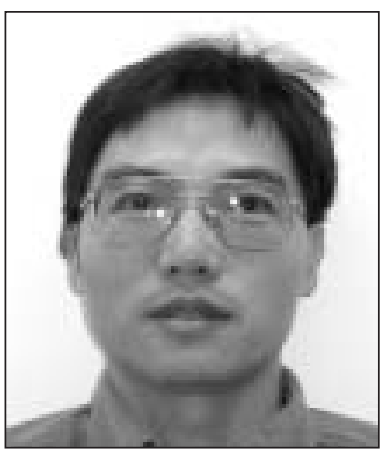

Chuangmin Liu

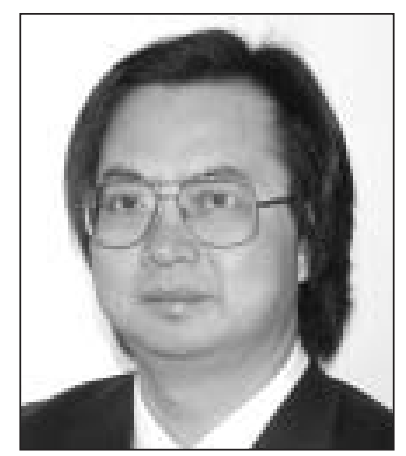

S.Y. Zhang

\section{Introduction}

Black spruce (Picea mariana (Mill.) BSP) is an economically important tree species in Canada. The species is highly valued for pulpwood, lumber and other products. Each year over 100 000 hectares of black spruce plantations are established in Canada (Zhang and Chauret 2001). Individual tree characteristics such as tree size (e.g., dbh or total tree height), taper, stem form, and crown size are key to tree value. However, only some of these characteristics are measured and recorded in forest inventories (e.g., dbh and total tree height). Therefore, foresters often directly relate tree or stand volume to selected tree characteristics that are relatively easy to measure. In fact, many inventories only record dbh as it can be easily measured at little cost. Tree height along with dbh is also commonly used as a predictor variable for estimating total tree volume, however. Tree height data are relatively more dif-

\footnotetext{
${ }^{1}$ Chuangmin Liu, Research Scientist, Forintek Canada Corp., 319 rue Franquet, Sainte-Foy, Québec G1P 4R4. E-mail: chuangmin.liu@ qc.forintek.ca

${ }^{2}$ Dr. S.Y. Zhang (Corresponding author), Senior Scientist and Group Leader, Forintek Canada Corp., 319 rue Franquet, Sainte-Foy, Québec G1P 4R4. E-mail: tony.zhang@qc.forintek.ca
} 
ficult and costly to collect and, hence, not all trees are measured for height. Consequently, height-diameter relationships are needed. Wood volume can be estimated using a tree volume equation based on dbh and height information (e.g., Bailey and Dell 1973, Siitonen 1993).

Most existing forest growth models have focused on wood volume. However, it is well known that each cubic meter of wood is not created equal in terms of lumber recovery (e.g., volume, quality, value) (Zhang et al. 1998). Trees with different characteristics can produce different lumber and chip volumes and thus different total tree values. A value-orientated utilization strategy is becoming more important in the forest industry in Canada. Thus, it is necessary to establish a relationship between tree characteristics and tree product recovery (e.g., lumber volume recovery, total product value recovery) in addition to wood volume. Product recovery is defined as an expression of the amount of product (nominal or actual) that can be manufactured from a given input of raw material. Establishment of a relationship between tree characteristics and product recovery will allow the potential value of individual trees and a stand to be estimated directly from those tree characteristics that are relatively easy to measure. Modeling of product recovery in relation to tree characteristics is useful to forest managers for a variety of management strategies, such as optimizing stand value as opposed to stand volume.

Several studies have shown that product recovery is closely related to tree characteristics such as dbh (e.g., Kellogg and Warren 1984, Malan 1988, Oberg 1989, Prestemon and Buongiorno 2000, Stevens and Barbour 2000, Zhang et al. 2002, Nagubadi et al. 2003). For example, the effect of tree characteristics on lumber recovery including lumber volume (e.g., Oberg 1989), grade yield (e.g., Fahey 1980, Prestemon and Buongiorno 2000, Beauregard et al. 2002) and product value in monetary units (Kellogg and Warren 1984, Briggs 1989, Prestemon and Buongiorno 2000) has been assessed. Recently, Zhang and Tong (2005) examined the regression relationships between tree characteristics and lumber volume recovery in jack pine (Pinus banksiana). However, regression relationships between four types of product recovery (i.e., lumber volume recovery, lumber value recovery, chip volume recovery, and total product value recovery) and tree size have not been established for black spruce to date. In addition, equations for height, total stem volume, product recovery as a whole have not been examined or quantified for black spruce plantations in northeastern Quebec.

In this study, we assessed the effectiveness of various regression models for predicting product recovery using several tree characteristics. Specifically, the purposes of this study were (1) to develop tree height-diameter models and total tree volume equations, and (2) to quantify the relationship between four product recoveries (lumber and chip volume recovery, lumber value, and total product value) and tree characteristics.

\section{Materials and Methods \\ Sample selection}

Sample trees were collected from two sites located in the Abitibi-Témiscaming Region, Quebec. On each site, three mature 90-100 year-old stands were systematically selected in order to cover different stand densities. In total, six stands with densities of $725,950,1200,1275,1550$, and 1825 stems/ha were chosen. From each stand, 30 sample trees from the merchantable dbh classes (e.g., 10, 12, $14 \mathrm{~cm} . .$. ) were sampled in 2002. However, due to various circumstances such as broken stems, the total sample size was reduced to 172 trees. These constituted the fit data set. Typically, an independent test data set should be used to validate the prediction accuracy of developed models. Therefore, 139 black spruce sample trees obtained from another study (Zhang and Chauret 2001) were used as an independent data set for model testing. A detailed description of the test data can be found in Zhang and Chauret (2001). The summary statistics for the fit and test data sets are presented in Table 1 .

\section{Tree measurements}

For each tree in the fit and test data sets, the following characteristics were measured: dbh outside bark, total tree height, tree height up to a 7-cm diameter top, crown width, crown length, clear log length, and diameters of the five largest

Table 1. Summary statistics of the fit data set (sample size $=172$ ) and of the test data set (sample size $=139$ )

\begin{tabular}{|c|c|c|c|c|c|c|c|c|}
\hline & $\begin{array}{c}\mathrm{DBH} \\
(\mathrm{cm})\end{array}$ & $\begin{array}{l}\text { Total } \\
\text { height } \\
(\mathrm{m})\end{array}$ & $\begin{array}{l}\text { Stem } \\
\text { taper } \\
(\mathrm{cm} / \mathrm{m})\end{array}$ & $\begin{array}{c}\text { Total } \\
\text { stem } \\
\text { volume } \\
(\mathrm{dm} 3 / \text { tree })\end{array}$ & $\begin{array}{c}\text { Lumber } \\
\text { volume } \\
\text { (dm3/tree) }\end{array}$ & $\begin{array}{c}\text { Lumber } \\
\text { value } \\
\text { (CAN\$/tree) }\end{array}$ & $\begin{array}{c}\text { Chip } \\
\text { volume } \\
(\mathrm{dm} 3 / \text { tree })(\end{array}$ & $\begin{array}{l}\text { Total } \\
\text { product } \\
\text { value } \\
\text { (CAN\$/tree) }\end{array}$ \\
\hline & \multicolumn{8}{|c|}{ Fit data } \\
\hline Minimum & 9.10 & 9.95 & 0.69 & 28.98 & 0.00 & 0.00 & 24.00 & 1.76 \\
\hline Maximum & 30.30 & 26.65 & 1.64 & 687.83 & 486.16 & 90.27 & 242.64 & 101.53 \\
\hline Mean & 16.18 & 16.92 & 1.11 & 176.95 & 103.53 & 17.72 & 83.14 & 21.73 \\
\hline \multirow[t]{2}{*}{ Standard deviation } & 5.00 & 3.55 & 0.20 & 139.23 & 101.74 & 18.59 & 47.96 & 20.91 \\
\hline & \multicolumn{8}{|c|}{ Test data } \\
\hline Minimum & 9.20 & 8.90 & 0.51 & 23.64 & 0.00 & 0.00 & 21.43 & 2.46 \\
\hline Maximum & 29.70 & 19.70 & 1.40 & 611.48 & 467.33 & 85.31 & 228.46 & 95.88 \\
\hline Mean & 16.60 & 15.00 & 1.00 & 163.35 & 90.39 & 15.86 & 74.70 & 19.21 \\
\hline Standard deviation & 3.88 & 2.36 & 0.20 & 125.95 & 88.92 & 15.11 & 51.38 & 17.54 \\
\hline
\end{tabular}


branches. The stem diameter and deformations were recorded in detail at intervals of $1 \mathrm{~m}$ along the stem so that the true stem shape could be acquired for Optitek simulations (Forintek Canada Corp. 1994). These data were also used to determine stem taper, total stem volume and merchantable stem volume for each stem.

\section{Sawing simulation}

Data from each sample tree in the fit and test data sets served as input for the sawing simulator Optitek developed by Forintek Canada Corp (1994). Optitek can be employed to simulate all operations in a softwood conversion mill, from bucking to optimized edging and trimming, including log breakdown and curve sawing. As wells, Optitek can "saw" an actual log in different sawmill layouts and product combinations. In this study, a stud mill was defined for eastern Canada to process the stems. This type of sawmill is typically used in eastern and central Canada. In the stud mill, the stems were first bucked into logs of $2.44 \mathrm{~m}$ ( 8 feet) in length, and then logs were sent to the mill to be "cut" into lumber with optimized lumber value recovery. Products from the stud mill were mostly $2.44 \mathrm{~m}$ long studs with various thickness and width dimensions (Forintek Canada Corp. 1994). The sawing simulator has been validated for the major eastern Canadian softwood species (e.g., black spruce and jack pine) and has been used extensively across Canada since 1994 (number of mills $=28$ ). The differences between predictions of product recovery from the sawing simulator Optitek and observed product recoveries from real sawmills are small (5-10\%). The predictions of product recovery from this stud sawmill simulation were used to represent the observed product recoveries from a real stud sawmill. Product recovery from a real stud sawmill was used to further validate the developed equations.

Lumber value was calculated for each piece based on the average market price for specific dimensions and grades. The market prices used in this study were based on five-year averages (1998-2002) calculated using lumber prices data from Quebec Forest Industry Council (2003). Prices were adjusted for inflation to the year 2002. Chip volumes were calculated for each tree by subtracting the total lumber volume from the total stem volume. The volume of sawdust was assumed to be $5 \%$ of the total stem volume. Chip and sawdust values were determined according to their volume and the market prices for black spruce chips (CAN\$111.08/ovendry metric ton) and sawdust (CAN\$20/ovendry metric ton). The total product value of each sample tree (in Canadian dollars (CAN\$)) was determined by summing the values of lumber, chips and sawdust from the tree. The results of four product recoveries from the stud sawmill simulation are summarized in Table 1.

\section{Model Development}

\section{Tree height-diameter models}

The relationship between tree height and diameter growth is usually described by non-linear mathematical models. A number of height-diameter equations have been developed for various tree species during the last few decades (e.g., Curtis 1967, Larsen and Hann 1987, Huang et al. 1992, Zhang 1997, Peng et al. 2001, Sharma and Zhang 2004). All of these equations used only $\mathrm{dbh}$ as an independent variable for estimating total height. Peng (1999) provided a detailed list of forms of height-dbh equations for different tree species. The
Chapman-Richards function is cited in the forestry literature as one of the best nonlinear growth functions for describing height-diameter relationships for various species (Zhang 1997, Fang and Bailey 1998, Peng et al. 2001, Sharma and Zhang 2004). We used the Chapman-Richards function to model the relationship between height and diameter for black spruce based on its flexibility and biologically interpretable coefficients (Pienaar and Turnbull 1973). The ChapmanRichards function for height can be expressed as

$$
\text { [1] } \hat{H}=1.3+a\left(1-e^{j D}\right)
$$

where $\hat{H}$ is the estimated total tree height $(\mathrm{m}), \mathrm{D}$ is outside bark tree diameter at breast height $(\mathrm{cm})$, and $\mathrm{a}, \mathrm{b}$, and $\mathrm{c}$ are regression coefficients estimating the asymptote, scale, and shape parameters, respectively.

\section{Total stem volume models}

The input variables to volume equations can include $\mathrm{dbh}$, height, stem taper, and interaction terms (i.e., multiplying variable together). Many forms of volume equations exist for different tree species (Honer et al. 1983, Shailer et al. 1998). To be simple, we selected four common equations to quantify the total stem volume in black spruce.

[2]

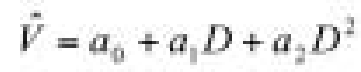

[3]

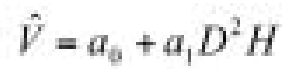

[4] $\hat{V}=a_{0}(D)^{\alpha_{1}}(H)^{\alpha_{1}}$

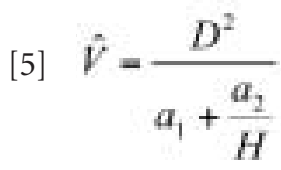

where $\hat{V}$ is the estimated total stem volume, inside bark, stump and top included $\left(\mathrm{dm}^{3}\right), \mathrm{H}$ is total tree height $(\mathrm{m}), \mathrm{D}$ is outside bark tree diameter at breast height $(\mathrm{cm}), a_{0}, a_{1}$, and $a_{2}$, are regression coefficients.

\section{Model development for product recovery}

Dbh, tree height, and stem taper were sufficient to predict total tree value recovery obtained from black spruce in a real stud sawmill (Aubry et al. 1998, Zhang et al. 2002). Other studies also indicated that tree size characteristics such as dbh had a major impact on product recovery (e.g., lumber value or volume recovery) from individual trees (e.g., Fahey 1980, Kellogg and Warren 1984, Beauregard et al. 2002, Zhang et al. 2002, Nagubadi et al. 2003). Therefore, we selected dbh, total height, and stem taper as independent (predictor) variables. Stem taper was calculated based on the tree height up to the 7-cm inside bark diameter top in this study.

The general regression form for product recovery was assumed as follows:

[6] $P_{j}=f(D, H, T)$ 
where $\mathrm{P}_{\mathrm{j}}$ represents the product recovery (i.e., lumber volume recovery $\left(\mathrm{dm}^{3}\right)$, lumber value recovery $(\mathrm{CAN} \$)$, chip volume recovery $\left(\mathrm{dm}^{3}\right)$, and total product value recovery (CAN\$)) from the jth tree, and $T$ is stem taper $(\mathrm{cm} / \mathrm{m})$.

Equation [6] can be extended to many forms. Based on some earlier studies (e.g., Ernst and Hann 1984, Kellogg and Warren 1984, Beauregard et al. 2002, Zhang et al. 2002, Nagubadi et al. 2003, Zhang and Tong 2004), we primarily examined two model forms: a multiple polynomial function and a power function.

[7] $\hat{P}=a_{0}+a_{1} D+a_{2} D^{2}+a_{3} D^{3}$

[8] $\hat{P}=a_{0}+\sum_{i=1}^{3}\left(a_{i} D^{\prime}+b_{i} H^{j}\right)+\sum_{j=1}^{2} \sum_{i=1}^{2}\left(d_{j k} D^{j} H^{j}\right)$

[9] $\hat{P}=a_{0}+\sum_{i=1}^{3}\left(a_{i} D^{i}+b_{i} H^{i}+c_{i} T^{i}\right)$ $+\sum_{i} \sum_{j} \sum_{i}\left(e_{0 k} D^{\prime} H^{j} T^{k}\right)$

[10] $\hat{P}=a_{0}(D)^{a_{3}}(H)^{a_{1}}$

[11] $\hat{P}=a_{0}(D)^{a_{1}}(H)^{a_{2}}(T)^{a_{3}}$

Where $\hat{P}$ is the estimated product recovery, $a_{i}(\mathrm{i}=0,1,2,3)$, $b_{i}(\mathrm{i}=1,2,3), c_{i}(\mathrm{i}=1,2,3), d_{i k}(\mathrm{j}=1,2 ; \mathrm{k}=1,2), e_{l i k}(\mathrm{l}=0$, $1,2 ; \mathrm{j}=0,1,2 ; \mathrm{k}=0,1,2)$ are the coefficients to be estimated. For Equation [9], one of $j, l, k$ is zero, and the sum of the remaining two of $j, l, k$ is not more than 3 .

\section{Model Evaluation}

The models were evaluated based on the multiple coefficient of determination $\left(R^{2}\right)$, the root mean square error (RMSE), the mean absolute error (MAE) and relative error (RE) of the predictions, and bias. The $R^{2}$, RMSE, MAE, RE, and bias were computed as follows:

[12] $R^{2}=1-\frac{\sum\left(Y_{j}-\hat{Y}_{j}\right)^{2}}{\sum\left(Y_{j}-\bar{Y}\right)^{2}}$

[13] RMSE $=\sqrt{\frac{\sum_{j=1}^{m}\left(Y_{j}-\hat{Y}_{j}\right)^{2}}{m}}$.

[14] MAE $=\frac{\sum_{j=1}^{n}\left|Y_{j}-\hat{Y}_{j}\right|}{m}$
[15] $R E(\%)=\frac{\frac{1}{m} \sum_{j=1}^{n}\left|Y_{j}-\hat{Y}\right|}{\bar{Y}} \times 100$

$[16] \operatorname{bias}(\%)=\frac{\frac{1}{m} \sum_{j=1}^{m}\left(Y_{j}-\hat{Y}_{j}\right)}{\bar{Y}} \times 100$

where $Y_{j}$ and $\hat{Y}_{j}$ are the observed response variable value of tree $j$ and predicted response variable value of tree $j$ for each regression model, respectively; $\bar{Y}$ is the mean of observed response variable value for the $m$ trees; $j=1,2, \ldots$, $\mathrm{m}$; and $\mathrm{m}$ is the number of trees. The RMSE, MAE, and RE provide an indication of model fit due to no cancellation between positive and negative values (Leduc et al. 2001). The smaller the RMSE, MAE and RE, the better is the model. Positive bias represents underprediction by the model and negative bias represents overprediction by the model. For model comparison among models, those statistical criteria were evaluated based on the test data set.

For each regression model, the normality of the residuals (observed - predicted) and heteroscedasticity were checked using the Shapiro-Wilk test (Shapiro and Wilk 1965) and plots of the residuals against predicted response variable values, respectively. SAS (SAS Institute Inc. 1999) was used for all computations.

\section{Results and Discussion \\ Height-diameter model}

The fitted Chapman-Richards equation and fit statistics for Equation [1] are presented in Table 2. The equation explained $80.30 \%$ of the total variance in total tree height using $\mathrm{dbh}$. The equation had a RMSE value of $1.40 \mathrm{~m} /$ tree and MAE value of $1.11 \mathrm{~m} /$ tree, respectively. Hence, the difference in $\mathrm{R}^{2}$ between the fit and test data sets was small. This indicated that the equation had a strong ability to generate accurate responses to new inputs. The equation gave predictions with a $\mathrm{R}^{2}$ value greater than 0.74 for the test data set (Table 2 ). The mean absolute prediction error and relative error were 1.56 $\mathrm{m} /$ tree and $10.4 \%$, respectively.

Height for each individual tree was estimated using this equation and the bias in estimating height was computed for all trees. The bias for the test data set was 5.6\%, indicating that the equation underestimated height overall. However, based on statistical criteria such as $\mathrm{R}^{2}$, RMSE, and MAE from both fit and test data sets, the equation was able to provide accurate height estimates.

\section{Total stem volume models}

All four regression models for the total stem volume and their statistics for fit and test data sets are listed in Table 2. All the models had high $R^{2}$ values greater than 0.97 based on the fit data. The differences in $\mathrm{R}^{2}$, RMSE, MAE between the fit and test data sets were small. Since model 3 had the highest $\mathrm{R}^{2}$ and lowest RMSE and MAE for both data sets, it appeared that it was best prediction equation for total stem volume. However, there were negligible differences in the fit of the four models. 


\begin{tabular}{|c|c|c|c|c|c|c|c|c|}
\hline \multirow{2}{*}{$\begin{array}{l}\text { Type of product } \\
\text { recovery }\end{array}$} & \multirow{2}{*}{$\begin{array}{l}\text { Model } \\
\text { number Fitted regression equation }\end{array}$} & \multicolumn{3}{|c|}{ Fit data set } & \multicolumn{4}{|c|}{ Test data set } \\
\hline & & $\mathrm{R}^{2}$ & RMSE & MAE & $\mathrm{R}^{2}$ & RMSE & MAE & $\mathrm{RE}(\%)$ \\
\hline Total tree height & $\vec{H}=1.3+21.4799\left(1-e^{-6 \text { ment }}\right)^{\text {Bnt }}$ & 0.8030 & 1.40 & 1.11 & 0.7453 & 1.98 & 1.56 & 10.40 \\
\hline \multirow[t]{4}{*}{ Total stem volume } & $\dot{V}=21.6645-7.90758 D+0.98728 D^{2}$ & 0.9732 & 23.01 & 13.97 & 0.9128 & 27.24 & 16.89 & 10.34 \\
\hline & $\hat{V}=8.5920+0.03106 D^{2} H$ & 0.9891 & 17.91 & 10.54 & 0.92 & 21.74 & 15.52 & 9.50 \\
\hline & $\dot{V}=0.043978 D^{\text {theists }} H^{\operatorname{csen} 30}$ & 0.9835 & 18.04 & 11.26 & 0.9215 & 23.37 & 15.78 & 9.66 \\
\hline & $\bar{V}=D^{2}\left(0.001454+29.7793 H^{-1}\right)^{-1}$ & 0.9864 & 20.37 & 11.63 & 0.9187 & 23.86 & 15.71 & 9.62 \\
\hline \multirow[t]{4}{*}{ Lumber volume } & $\hat{P}=34.78616-10.83211 D+0.85120 D^{2}$ & 0.9496 & 22.96 & 13.83 & 0.9165 & 26.60 & 17.28 & 19.12 \\
\hline & $p=-17.83773+0.02242 D^{2} H$ & 0.9651 & 19.07 & 11.26 & 0.9384 & 20.91 & 16.31 & 18.05 \\
\hline & $10 \quad \hat{P}=0,0008020^{2.4502} H^{1.26 s i s}$ & 0.9390 & 27.66 & 15.74 & 0.9011 & 29.41 & 18.71 & 20.71 \\
\hline & $11 \dot{P}=0.000800 D^{2.5609} H^{1.3955} T^{-40425}$ & 0.9390 & 27.99 & 15.84 & 0.9016 & 28.37 & 18.53 & 20.50 \\
\hline \multirow[t]{4}{*}{ Lumber value } & $7 \quad \dot{P}=7.42958-2.25544 D+0.16321 D^{2}$ & 0.9529 & 4.06 & 2.41 & 0.9290 & 5.11 & 4.09 & 25.79 \\
\hline & $\hat{P}=-4.47084+0.0041 D^{2} H$ & 0.9668 & 3.39 & 2.04 & 0.9341 & 4.97 & 3.52 & 22.19 \\
\hline & $10 \hat{P}=0.000040 D^{238 i 4} H^{1 \text { teen }}$ & 0.9444 & 6.46 & 3.34 & 0.9238 & 7.57 & 4.23 & 26.67 \\
\hline & $11 \hat{P}=0.000039 D^{2 \times 517} H^{1.31006} T^{\text {-awans }}$ & 0.9448 & 6.27 & 3.31 & 0.9242 & 7.35 & 4.15 & 26.17 \\
\hline \multirow[t]{4}{*}{ Chip volume } & $\hat{P}=-11.44109-2.40615 D+0.19409 D^{2}$ & 0.9466 & 11.15 & 8.15 & 0.9004 & 15.22 & 10.98 & 14.70 \\
\hline & $\hat{P}=-0.08684+0.15130 D H+0.13731 D^{2}$ & 0.9528 & 10.47 & 7.58 & 0.9281 & 13.31 & 9.32 & 12.48 \\
\hline & $10 \hat{P}=0.26265 D^{1.51324} H^{03564}$ & 0.9583 & 10.51 & 7.48 & 0.9152 & 13.86 & 9.85 & 13.19 \\
\hline & $11 \hat{P}=0.27350 D^{1017} H^{0.2 \pi n s} T^{0.12 n ?}$ & 0.9586 & 10.53 & 7.45 & 0.9156 & 13.87 & 9.78 & 13.09 \\
\hline \multirow[t]{4}{*}{ Total product value } & $\hat{P}=7.16887-2.19657 D+0.17478 D^{2}$ & 0.9608 & 4.16 & 2.45 & 0.9463 & 4.77 & 3.39 & 17.65 \\
\hline & $8 \quad P=-3.3270+0.00463 D^{2} H$ & 0.9743 & 3.36 & 1.95 & 0.9512 & 4.25 & 2.57 & 13.38 \\
\hline & $10 P=0.000411 D^{2.544+1} H^{2.2128}$ & 0.9752 & 4.59 & 2.58 & 0.9493 & 4.65 & 2.84 & 14.78 \\
\hline & $11 \hat{P}=0.000427 D^{20253} H^{1.3139} T^{0.1214 i}$ & 0.9753 & 4.51 & 2.54 & 0.9502 & 4.61 & 2.72 & 14.16 \\
\hline
\end{tabular}

Note: Model 9 was reduced to the same form as the Model 8 after stepwise selection.

\section{Product recovery models}

Table 2 lists the regression results for predicting product recovery and tree characteristics for all the fitted model forms using the fit data set. Note that model 9 was reduced to the same form as model 8 after stepwise selection at the 0.05 probability level (Table 2). In model 11, all parameters except for stem taper were statistically significant at the 0.05 probability level. By including stem taper in the power function (model 11), there was almost no increase of $\mathrm{R}^{2}$ compared to model 10, which includes only dbh and tree height. This suggests that tree taper did not contribute significantly to product recovery and over-parameterization may exist in these power functions (Draper and Smith 1981). All models developed had $R^{2}$ values greater than 0.90 from the fit data set, indicating that most of the variation in product recovery was explained by the tree characteristics used.

The $\mathrm{R}^{2}$, RMSE, and mean absolute error (MAE), and relative error (RE) of prediction for the test data are summarized in Table 2. Model 8 was more accurate in predicting product recovery for the test data than any other model. However, model 7 using DBH alone had values of $\mathrm{R}^{2}$, RMSE, MAE, and RE comparable to model 8, as did models 10 and 11 .

Predictions of product recovery from the stud sawing simulator were used to develop and test the equations for product recovery. Differences between predictions of product recovery from the stud sawing simulator and actually observed product recoveries from real stud sawmills may exist. It is important to further validate the product recovery equations using observed product recoveries from real stud sawmills. Lumber volume recovery is the most important recovery type among the four types of product recoveries, in that it determines the values of the other three types of product recoveries. Also, the actual lumber volume recovery from a real stud sawmill for the test dataset (139 sample trees) was available. Therefore, we used the actual lumber volume recovery data from the real stud sawmill to further validate the accuracy of models 7,8 , and 10 . The reason for choosing these three models was that they were considered to better quantify the relationships of the simulated lumber volume recovery with $\mathrm{dbh}$ and tree height based on the fit data. The relative error of prediction and bias are summarized in Table 3. The overall mean prediction errors for models $7,8,10$ were $42.57 \%, 26.30 \%$, and $22.25 \%$, respectively. It appears that, on average, model 8 and model 10 predicted the actual lumber volume recovery more accurately than did model 7 . The overall biases for models 7,8 , and 10 were $-35.18 \%,-10.37 \%$, $5.61 \%$, respectively. This indicated that the models over-predicted the lumber volume recovery, overall. We believe this happened because in the real stud mill tree factors not incorporated into the stud sawing simulator (e.g., rot, external stem defects) might have had negative impacts on lumber volume recovery.

The above models performed better for small- and medium-sized trees (10-22 cm dbh classes), and had smaller prediction errors and biases. On the other hand, they yielded relatively larger prediction errors and biases for the $24 \mathrm{~cm} \mathrm{dbh}$ 
Table 3. The relative error of predictions and bias in each DBH class for model validation using actual observed lumber volume recovery from a real stud mill

\begin{tabular}{llccccrrrr}
\hline & & \multicolumn{3}{c}{ Relative error (\%) } & & \multicolumn{3}{c}{ Bias (\%) } \\
\cline { 3 - 5 } \cline { 7 - 8 } $\begin{array}{l}\text { dbh } \\
\text { class }\end{array}$ & $\begin{array}{l}\text { Number } \\
\text { of trees }\end{array}$ & Model 7 & Model 8 & Model 10 & & Model 7 & Model 8 & Model 10 \\
\hline 10 & 15 & 27.00 & 34.44 & 25.26 & & -4.24 & 27.55 & 4.24 \\
12 & 14 & 28.94 & 25.23 & 24.73 & & -15.01 & -2.73 & 4.09 \\
14 & 19 & 22.36 & 20.44 & 27.47 & & -1.83 & 12.79 & 26.50 \\
16 & 24 & 31.23 & 15.31 & 16.65 & & -29.55 & -7.16 & -10.75 \\
18 & 24 & 53.87 & 27.04 & 17.17 & & -54.19 & -25.98 & 8.91 \\
20 & 24 & 47.15 & 23.40 & 13.56 & & -47.02 & -23.24 & -11.62 \\
22 & 12 & 56.51 & 25.16 & 19.28 & & -56.46 & -24.90 & -14.67 \\
24 & 7 & 73.18 & 39.36 & 33.84 & & -73.16 & -39.33 & -33.81 \\
\hline Total & 139 & 42.57 & 26.30 & 22.25 & & -35.18 & -10.37 & -5.61 \\
\hline
\end{tabular}

class or above in the validation data set (Table 3). Black spruce is a shade-tolerant species, and the stem growth and shape may have less variation across small- and medium-sized trees.

The Shapiro-Wilk test indicated that the normality assumption for each regression equation held with a p-value greater than 0.05 . The plots of residuals confirmed that the residuals for all the developed regression models were evenly distributed over the predicted product recovery and had no obvious trend. Also, based on the statistical criteria $\left(R^{2}\right.$, RMSE, MAE, and RE), the regression models developed from the fit data set were suitable to predict their corresponding response variables (total tree height, total stem volume, and product recoveries) in black spruce. The test data confirmed that the regression models had high prediction accuracies for the response variables in terms of $\mathrm{R}^{2}$, RMSE, MAE, and RE.

The results showed that model 2 and model 7 could be used to predict the total stem volume and product recovery, respectively, if only dbh data was available. Generally, the models with both dbh and tree height provided the best estimates of the total stem volume and product recoveries. Due to the geometry of a tree stem, dbh and tree height are directly related to log volume. For example, the contents of cylinders, cones, or paraboloids are functions of diameter squared times height. Therefore, the combination of dbh and height were important factors for quantifying the total stem volume and product recovery as well. Aubry et al. (1998) reported that the size of the stem determined the number of boards per $\log$ (diameter effect) and the number of logs per tree (height effect). Both number of logs and number of boards per log have a major impact on lumber volume recovery and thus tree total product value. Tree value depends primarily on its $\mathrm{dbh}$, and secondly on its tree height (Zhang and Chauret 2001, Zhang et al. 2002). Therefore, the regression models described the relationship between the selected tree characteristics and product recovery.

\section{Conclusion}

Regression approaches were used to develop equations for estimating total tree height, total stem volume, and product recoveries from a stud sawing simulator. All models except model 1 explained over $90 \%$ of the total variance in their corresponding response variables for both fit and test data sets.
Based on statistical criteria ( $\mathrm{R}^{2}$, RMSE, MAE, and RE), tests for normality of residuals, and examinations of residual plots, the regression models developed were suitable for predicting their corresponding response variables in black spruce plantations. The general tree-level models for the product recovery allow the estimation of the product recovery of individual trees and of a forest stand before it is harvested.

In this paper, we have mainly focused on the development of general tree-level product recovery models for black spruce plantations. The results of this study are limited to plantation black spruce trees. According to the product recovery models, the lumber recovery and chip volumes would be similar for a $\log$ of equivalent diameter and taper irrespective of stand origin. However, the density of wood (lumber) in plantation trees may be different from that of in trees from natural origin stands. Research is still required to compare the results (equation parameter estimates and predictions) obtained in this study to those for naturally grown black spruce in order to produce reasonable estimations of product recovery for both natural and managed black spruce stands.

\section{References}

Aubry, C.A., W.T. Adams T.D. and Fahey. 1998. Determination of relative economic weights for multitrait selection in coastal Douglasfir. Can. J. For. Res. 28: 1164-1170.

Bailey, R.L. and T.R. Dell. 1973. Quantifying diameter distributions with the Weibull function. For. Sci. 19: 97-104.

Beauregard, R.L, R. Gazo and R.D. Ball. 2002. Grade recovery, value, and return-to-log for the production of NZ visual grades (cuttings and framing) and Australian machine stress grades. Wood Fiber Sci. 34 (4): 485-502.

Briggs D.G. 1989. Tree value system: description and assumptions. General Technical Report Pacific Northwest Research Station, USDA Forest Service. No. PNW-GTR-239. 24 p.

Curtis R.O. 1967. Height-diameter and height-diameter-age equations for second growth Douglas fir. For. Sci. 13: 365-375.

Draper, N.R. and H. Smith. 1981. Applied regression analysis. Second edition. John Wiley and Sons, New York. 709 p.

Ernst, S. and D.W. Hann. 1984. Volume and value prediction for young-growth true fir trees. For. Sci. 30: 871-882.

Fang, Z. and R.L. Bailey. 1998. Height-diameter models for tropical forests on Hainan Island in southern China. For. Ecol. Manage. 110: 315-327. 
Fahey, T.D. 1980. Grading second-growth Douglas-fir by basic tree measurements. J. For. 4: 206-216.

Forintek Canada Corp. 1994. Optitek: User's guide. Forintek Canada Corp., Sainte-Foy, Quebec. 185 pp.

Honer, T. G., M.F. Ker and I.S. Alemdag. 1983. Metric timber tables for the commercial tree species of central and eastern Canada. Maritimes For. Res. Centre. Info. Rep. M-X-140.

Huang, S., S.J. Titus and D.P. Wiens. 1992. Comparison of nonlinear height-diameter functions for major Alberta tree species. Can. J. For. Res 22: 1297-1304.

Kellogg, R. M. and W.G. Warren. 1984. Evaluating western hemlock stem characteristics in terms of lumber value. Wood Fiber Sci. 16(4): 583-597.

Larsen, D.R. and D.W. Hann. 1987. Height-diameter equations for seventeen tree species in southwest Oregon. Oregon State. Univ., For. Res. Lab. Pap. 4.

Leduc, D.J., T.G. Matney, K.L. Belli and V.C. Baldwin Jr. 2001. Predicting diameter distributions of longleaf pine plantations: a comparison between artificial neural networks and other accepted methodologies. USDA Forest Service, Southern Research Station. Research Paper SRS-25. 18 p.

Malan, F.S. 1988. Relationships between growth stress and some tree characteristics in South African growth Eucalyptus Grandis. South African Forestry Journal 144: 43-46.

Nagubadi, R.V., R.D. Fight and R.J. Barbour. 2003. Value a log: alternative approaches. USDA For. Serv. Res. Note, PNW-RN-541. 15 p. Oberg, J.C. 1989. Impacts on lumber and panel products. Proceedings of Southern Plantation Wood Quality Workshop. June 6-7, 1989, Athens, Georgia.

Peng, C.H. 1999. Nonlinear height-diameter models for nine tree species in Ontario boreal forests, Ministry of Natural Resources, Ontario Forest Research Institute, OFRI-Rep. 155. Ontario.

Peng, C., L. Zhang and J. Liu. 2001. Developing and validating nonlinear height-diameter models for major tree species of Ontario's boreal forests. North. J. Appl. For. 18: 87-94.

Pienaar, L.V. and K.J. Turnbull. 1973. The Chapman-Richards generalization of von Bertalanffy's growth model for basal area growth and yield in even-age stands. For. Sci. 19: 2-22.

Prestemon, J.P. and J. Buongiorno. 2000. Determinants of tree quality and lumber value in natural uneven-aged southern pine stands. Can. J. For. Res. 30: 211-219.
Quebec Forest Industry Council. 2003. -2002- the yearbook. Economics and Markets Department, Quebec Forest Industry Council, Quebec.

SAS Institute Inc. 1999. SAS/STAT users guide. Version 8. SAS Institute Inc., Cary, N.C.

Shailer, S., J.A. Kershaw, and P. Zundel. 1998. Comparison of total volume equations for use in southwestern New Brunswick. Research Report prepared for Georgia Pacific (The Timber Company), St. Croix District.

Sharma, M. and S.Y. Zhang. 2004. Height-diameter models using stand characteristics for Pinus banksiana and Picea mariana. Scand. J. For. Res. 19: 442-451.

Shapiro, S.S. and M.B. Wilk. 1965. An analysis of variance test for normality (complete samples). Biometrika 52: 591-611.

Siitonen, M. 1993. Experiences in the use of forest management planning models. Silva Fennica 27: 167-178.

Stevens, J.A. and R.J. Barbour. 2000. Managing the stands of the future based on the lessons of the past: estimating western timber species product recovery by using historical data. USDA For. Serv. Res. Note, PNW-RN-528. 9 p.

Zhang, L. 1997. Cross-validation of non-linear growth functions for modelling tree height-diameter relationships. Ann. Bot. 79: 251-257.

Zhang, S.Y., Y. Corneau and G. Chauret. 1998. Impact of precommercial thinning on tree and wood characteristics, product quality and value in balsam fir. Canadian Forest Service No.39, Forintek Canada Corp. Sainte-Foy, Quebec. 77 p.

Zhang, S.Y. and G. Chauret. 2001. Impact of initial spacing on tree and wood characteristics, product quality and value recovery in black spruce (Picea mariana). CFS Rep. No.35, Forintek Canada Corp. Sainte-Foy, Quebec.

Zhang, S.Y., G. Chauret, H.Q. Ren and R. Desjardins. 2002. Impact of plantation black spruce initial spacing on lumber grade yield, bending properties and MSR yield. Wood Fiber Sci. 34(3): 460-475. Zhang, S.Y. and Q.J. Tong. 2005. Modelling simulated product recovery in relation to tree characteristics in jack pine using sawing simulator Optitek. Annal For. Sci. 62: 219-228. 